\title{
Sposoby wyrażania sympatii w rozmowach zapośredniczonych medialnie (na przykładzie serwisu społecznościowego Facebook.com)
}

\begin{abstract}
Chudzik Anna, Sposoby wyrażania sympatii w rozmowach zapośredniczonych medialnie (na przykładzie serwisu społecznościowego Facebook.com) (Methods of Expressing Liking Through the Media [on the Example of Facebook.com]). "Poznańskie Studia Slawistyczne" 9. Poznań 2015. Publishing House of the Poznań Society for the Advancement of the Arts and Sciences, pp. 19-33. ISSN 2084-3011.

The main theme of the article centers on the methods of expressing liking which is understood as a positive attitude towards another person functioning in the Internet. The aim of the paper is to show and discuss elements of communication and language pragmatics typical for emotive speech, including the elements which are results of the new media. The theoretical part concerns two aspects: 1) definition of the emotive (expressive) function in linguistics and of the terms describing phenomena which are related to the science of communication; 2) the Internet as a new tool and an environment for social communication. The analysis is conducted on the written data produced by the Facebook community. Conclusions concern the observed patterns of form, intentional content and functions of written production expressing liking.
\end{abstract}

KeYwords: emotive function; interpersonal communication; Internet communication; new media; communicative intention; emotions; liking; language pragmatics; semiotics

\section{Wstęp}

Tematem artykułu są sposoby wyrażania sympatii w przestrzeni Internetu, rozumiane jako ekspresja pozytywnego nastawienia do drugiej osoby. Celem rozważań jest ukazanie elementów komunikacyjnych i pragmalingwistycznych zarówno typowych dla wypowiedzi emotywnych, jak i będących efektem wykorzystania nowego medium. Wstępne założenia teoretyczne dotyczą dwóch zagadnień: po pierwsze definicji 
funkcji emotywnej w językoznawstwie i terminów opisujących pokrewne zjawiska w nauce o komunikowaniu, po drugie Internetu jako nowego środowiska komunikacji społecznej, w tym publicznej i interpersonalnej. W części analitycznej zostaną zbadane wypowiedzi użytkowników serwisu społecznościowego Facebook.com. Wnioski dotyczą zauważonych prawidłowości związanych z formą, intencją i funkcją wypowiedzi wyrażających sympatię.

\section{Funkcja emotywna w komunikacji interpersonalnej}

Wśród badaczy języka nie ma zgodności zarówno co do definicji funkcji emotywnej, jak i zakresu zjawisk (językowych i niejęzykowych), z którymi można ją powiązać. Pod przywołaną nazwą w modelu Romana Jakobsona znajduje się jedna z sześciu podstawowych funkcji języka, a właściwie: wypowiedzi (Furdal 2000: 43). Jest ona ,ześrodkowana na (nadawcy $^{1}$, wskazuje na bezpośrednie wyrażenie postawy mówiącego wobec tego, o czym on mówi. Chodzi tu o wywarcie wrażenia pewnej emocji, prawdziwej lub udanej" (Jakobson 1989: 82). Wyróżnione elementy definicji ${ }^{2}$ to te, $\mathrm{z}$ którymi inni badacze zjawiska podejmowali dyskusję ${ }^{3}$.

Pierwsza kwestia dotyczy treści wyrażania siebie. Jakobson mówi z jednej strony o „emocjach”, z drugiej, bardziej ogólnie, o „postawie”. Przywołane przykłady także nie rozjaśniają stanowiska zajmowanego przez badacza: jako egzemplifikacje czystej emotywności podaje on wykrzykniki, a także, nieco dalej, ekspresję zarówno gniewu, jak i ironii, która ma raczej charakter modalnościowo-wartościujący niż emocjonalny (Jakobson 1989: 82-83). Renata Grzegorczykowa z kolei wypowiedzi o funkcji ekspresywnej przypisuje wyrażanie nie tylko emocji, ale też woli

${ }^{1}$ W tekście polskiego thumaczenia jest: ,ześrodkowany na adresacie” - to błąd w tłumaczeniu, powinno być: ześrodkowany na nadawcy. Błąd wynika zapewne z podobieństwa angielskiego addresser (nadawca) do addressee (adresat, odbiorca).

${ }^{2}$ Wszystkie wyróżnienia w tekście, także w obrębie cytatów, pochodzą od autorki artykułu.

${ }^{3}$ W Polsce m.in. Antoni Furdal i Janusz Lalewicz; cf. przegląd stanowisk krytycznych wobec koncepcji Jakobsona (Grzegorczykowa 1991: 12-14). 
i sądów (Grzegorczykowa 1991: 24). Czy więc funkcja ta dotyczy wyłącznie ujawniania uczyć, czy także postaw modalnych, wolicjonalnych, aksjologicznych?

Choć nie ma wątpliwości, że funkcja emotywna służy wyrażeniu się nadawcy, u Jakobsona zwraca uwagę sformułowanie: „wywarcie wrażenia" (implikujące: na kimś). W takim ujęciu nie chodzi o spontaniczne, naturalne wyrażanie siebie, a o celowe, w pełni świadome wywieranie na odbiorcy wrażenia, wywoływania pewnych emocji w celu uzyskania zaplanowanego efektu perlokucyjnego. Inną koncepcję przedstawia Kazimierz Polański w Encyklopedii językoznawstwa ogólnego. Według niego funkcja ekspresywna polega na ,wyrażaniu (zdradzaniu) za pomocą wypowiedzi jęz. pewnych cech nadawcy” (Polański 2003: 190). Badacz zalicza wypowiedzi o funkcji ekspresywnej do sygnałów o „stanie fizjologicznym i psychicznym" nadawcy. Są to znaki naturalne i jako takie nie stanowią elementów systemu językowego (z nielicznymi wyjątkami, jak formy hipokorystyczne). Tymczasem według propozycji Antoniego Furdala funkcja emocjonalna, której celem jest przekaz emocji nadawcy, to kategoria odmienna od funkcji ekspresywnej, mającej „,charakter biologiczny” i służącej wyrażeniu się nadawcy, ale „nie w celu komunikacyjnym", tj. bez koniecznej obecności odbiorcy (Furdal 2000: 50, 55). Przyjmując to rozróżnienie i odsuwając na margines niekomunikatywne zachowania ekspresywne, można zadać dwa kolejne pytania: czy realizacja funkcji emotywnej jest spontaniczna i służy wyrażeniu siebie, czy też jest przemyślana, intencjonalna i świadomie podejmowana w celu wywarcia wrażenia?

Kolejny, wart komentarza, element definicji dotyczy autonomiczności funkcji. Wspominając powyżej o ,adresacie”, zauważono, że komunikat tworzony z myślą o nim nie jest czystą ekspresją nadawcy, ale zawiera także aspekt konatywny. Jakobson nie zakłada zresztą wyłączności występowania funkcji, a jedynie dominację niektórych z nich: „Odmienność każdorazowego aktu mowy polega nie na monopolu którejś z tych funkcji, ale na odmiennym porządku hierarchicznym" (Jakobson 1989: 82). Problem naturalnej wielofunkcyjności wypowiedzi pojawia się także w rozważaniach cytowanej już Renaty Grzegorczykowej, która pisząc o „czystej” ekspresji, dodaje, że chodzi tu o „wypowiedź idealną”, gdyż „W praktyce nadawca liczy się w pewien sposób z obecnością odbiorcy” 
(Grzegorczykowa 1991: 24). W innym miejscu badaczka rozpatruje relację między funkcją poznawczą a ekspresyjną, dochodząc do wniosku, że ta ostatnia może zostać potraktowana jako specyficzny rodzaj funkcji poznawczej, „gdy przedmiotem (tematem) wypowiedzi jest emocja nadawcy" (Grzegorczykowa 1991: 13). Wydaje się więc, że nieczęste są wypowiedzi, w których funkcja emotywna nie wiąże się z równocześnie realizowaną funkcją poznawczą, konatywną czy fatyczną, a nawet poetycką (jak np. wybór sposobu wyrażenia emocji).

Roman Jakobson zauważa także (biorąc zapewne pod uwagę również wypowiedzi literackie) znaczenie ,emocji prawdziwej lub udanej”, czyli porusza zagadnienie naturalności danego aktu wyrażania emocji oraz szczerości intencji nadawcy. Funkcją, a więc celem wypowiedzi emotywnej, może być symulacja wrażenia odczuwania emocji. Oznacza to, że nadawca niekoniecznie doznaje określonych emocji: może jedynie realizować znany mu model językowo-komunikacyjnego wyrażania ich. Wypowiedzi emotywne ulegają procesowi rytualizowania (Tabakowska 2001: 211-212). Należy jednak pamiętać, że prawdziwa intencja nadawcy nie jest tożsama $\mathrm{z}$ intencją konwencjonalnie odczytywaną z wypowiedzi. Dotyczy to różnych form manipulacji i oszustwa, ale także mniej jednoznacznych sytuacji, jak pochlebstwa (Drabik 2004: 26-39) czy „białe kłamstwa” (Antas 2000: 260-261). Sama kategoria intencjonalności nie jest elementem systemu językowego, ma charakter pragmalingwistyczny - wyrażana jest w akcie illokucji (Grzegorczykowa 2001: 76-77). John R. Searle w swojej teorii aktów mowy nie bierze pod uwagę ukrytych intencji ${ }^{4}$, gdyż jeden z warunków skutecznego działania za pomocą języka zakłada szczerość nadawcy (1987: 81). Badacz omawia kwestię jawności intencji na poziomie konwencji językowych, pisząc o aktach bezpośrednich, w których intencja wynika $\mathrm{z}$ aktu lokucji, oraz pośrednich, w których intencja jest odczytywana dzięki wnioskowaniu implikacyjnemu (Grzegorczykowa 2001: 78) $)^{5}$.

Model Jakobsona bywa krytykowany za linearność nieprzystającą do rzeczywistych sytuacji komunikacyjnych, mających wielostronny

\footnotetext{
${ }^{4}$ Choć omawia np. problem nieszczerych obietnic (Searle 1987: 83-84).

${ }^{5}$ Krystyna Pisarkowa, idąc jeszcze dalej, pokazuje, że rzeczywista intencja wypowiedzi nie zawsze musi być jawna nawet dla samego nadawcy (Pisarkowa 1994: 12-13).
} 
i złożony charakter. Warto przywołać w tym miejscu rozważań model komunikacji Friedemanna Schultza von Thuna, który rozpatruje wypowiedzi - ,pakiety złożonych informacji” - na czterech płaszczyznach przekazu: rzeczowej, ujawniania siebie, apelu i relacyjnej ${ }^{6}$ (Schulz von Thun 2001: 23-29). Trzy pierwsze z wymienionych aspektów odpowiadają trzem podstawowym funkcjom języka z modelu Karla Bühlera (a za nim Jakobsona). Analizując płaszczyznę ujawniania siebie, Schultz von Thun odróżnia wyrażenie siebie (zwykle wolicjonalne) od odsłonięcia siebie (mimowolnego) (Schultz von Thun 2001: 25). Badacz wyodrębnił także z omawianej płaszczyzny aspekt wzajemnych relacji jako osobną funkcję i poziom interakcji komunikacyjnej. Płaszczyzna ta, na której dochodzi do negocjowania wizerunków i relacji pomiędzy uczestnikami aktu komunikacji, wydaje się istotniejsza funkcjonalnie i bardziej emocjonalna niż poziom ujawniania siebie. Ma przy tym charakter niesystemowy i wymaga analizy pragmalingwistycznej konkretnej sytuacji komunikacyjnej ${ }^{7}$.

Wobec powyższych uwag, trudno zgodzić się z upraszczającym założeniem, że funkcja emotywna to tylko wyrażanie ,ja”. Po pierwsze, ekspresja ta bierze prawie zawsze pod uwagę adresata ${ }^{8}$; po drugie, autoujawnianie jest świadomą, zgodną z założonym celem, prezentacją siebie innym; po trzecie: ujawnianie emocji towarzyszy także uzgadnianiu stosunków pomiędzy uczestnikami aktu komunikacyjnego.

Kwestia samej natury uczuć, emocji, afektów i nastrojów, będących złożonymi fizjologiczno-psychicznymi reakcjami organizmu na bodźce, to jedno z ważniejszych zagadnień z zakresu psychologii społecznej. „Emocja odnosi się do uczucia i związanych z nim myśli, stanów psychicznych i biologicznych oraz zakresu skłonności do działania” - pisze Daniel Goleman i wylicza podstawowe „rodziny emocji”: złość, smutek, strach, zadowolenie, miłość, zdziwienie, wstręt i wstyd (Goleman 1997: 442-443). Rzeczywiste stany emocjonalne są mieszanką różnych emocji, które scharakteryzować można pod względem treści (typów odczuć),

${ }^{6}$ Autor modelu korzysta z dorobku wcześniejszych badaczy komunikacji społecznej, m.in. Paula Watzlawicka (1967), który wyróżnił płaszczyznę relacji w wypowiedzi (obok płaszczyzny treści).

${ }^{7}$ Zapewne $\mathrm{z}$ tego powodu była pomijana w językoznawczych rozważaniach na temat funkcji języka i wypowiedzi, a wydaje się pomocna do analizy sposobów wyrażania emocji.

${ }^{8} \mathrm{Z}$ wyjątkiem zupełnie spontanicznych reakcji werbalnych i niewerbalnych. 
znaku (wartości dodatniej lub ujemnej) oraz stopnia natężenia (siły uczucia) (Strelau, Jurkowski, Putkiewicz 1975: 134).

Interesująca mnie w niniejszym tekście postawa emocjonalna odczuwania i okazywania sympatii jest związana z jednoznacznie pozytywnymi uczuciami, składającymi się na rodzinę miłość, takimi jak: podziw, akceptacja, życzliwość, ufność, uprzejmość, skierowanymi ku osobie, z którą mamy poczucie bliskości i więzi. Stopień natężenia odczuwanych emocji może być różny, jednak wyklucza się skrajnie silne (afektywne); to raczej długotrwała postawa emocjonalna niż chwilowe, bardzo mocne odczucie 9 .

Przez językowe i komunikacyjne wyrażanie sympatii rozumiem zatem wypowiedzi, których dominującą, jawną i uświadamianą funkcją jest ujawnienie pozytywnego nastawienia do drugiej osoby. Dodatkowo akty te służą (w sposób uświadamiany lub nieświadomy) tworzeniu opartych na poczuciu więzi (psychicznej, intelektualnej, praktycznej) relacji z odbiorcą, autoprezentacji nadawcy oraz wywieraniu wrażenia na odbiorcy. Mogą także mieć za zadanie realizację innych (jawnych lub niejawnych) intencji nadawcy.

\section{Nowa sytuacja komunikacyjna - wirtualna rozmowa}

Internet, będący wynalazkiem komunikacyjnym, wpłynął na sposoby realizowania się różnych poziomów interakcji społecznych. Medium można rozumieć jako kod, narzędzie, kanał, a nawet instytucję przekazu komunikatów (Pisarek 2008: 82-84) - Internet jest medium w każdym z wymienionych znaczeń, dodatkowo najbardziej złożonym i konwergentnym spośród dotychczas dostępnych człowiekowi środków przekazu. Wirtualna sieć łącząca ludzi charakteryzuje się dodatkowo jeszcze jedną cechą: według Neila Postmana jest ,społecznym i intelektualnym środowiskiem wytworzonym przez maszynę" (Postman 2002: 37).

Internet wchłonął wszystkie dotychczasowe sposoby komunikacji, wytworzył także własne (Pisarek 2008: 145). Jest środowiskiem i na-

${ }^{9} \mathrm{Cf}$. słownikowe definicje: „uczucie polegające na lubieniu kogoś lub czegoś, przyjazny, przychylny stosunek do kogoś lub czegoś” (Dunaj 1996: 372); ,,̇yczliwy lub przyjazny stosunek wobec kogoś lub czegoś" (Słownik języka polskiego PWN, <http://sjp.pwn.pl/>, 20.04.2014). 
rzędziem zarówno komunikacji interpersonalnej, jak i grupowej, publicznej czy masowej. Tradycyjny podział poziomów komunikacji na prywatną (definiowaną jako interakcja między jednostkami), publiczną (asymetryczną komunikację jednostki z dużą grupą odbiorców) i masową (będącą medialnym jednostronnym rozpowszechnianiem informacji) (Winterhoff-Spurk 2007: 14) w dobie Internetu okazuje się nieadekwatny (Pisarek 2008: 90-95). Akty komunikacji w interesującym mnie portalu społecznościowym wyróżnia jednoczesność charakteru interpersonalnego i publicznego. Wymianę zdań między dwiema osobami na otwartym profilu (tzw. tablicy lub osi czasu) może obserwować nieskończenie wielu użytkowników.

Rozmowa prowadzona w środowisku serwisów społecznościowych podobnych do Facebooka w porównaniu do rozmowy bezpośredniej uległa istotnym modyfikacjom. Zmiany te wynikają w pierwszej kolejności z nowych możliwości technicznych (inny kanał komunikacji i kody semiotyczne), w drugiej zaś z charakteru tworzących się w sieci społeczności i ich wpływu na nastawienie poznawcze jednostki (Chudzik 2012).

Kod dostępny uczestnikom rozmowy na Facebooku to przede wszystkim narzędzia językowe (wersja e-pisma), wzbogacone środkami o charakterze wizualnym i audialnym. W porównaniu do rozmowy face to face najbardziej zauważalne różnice to: brak równoczesnego sprzężenia zwrotnego (asynchroniczna wymiana replik); brak komunikatów niewerbalnych (zwłaszcza gestów i mimiki) i parawerbalnych (akcentu, intonacji, dźwięków parajęzykowych); inne typy deiks (hiperlinki) (Galimberti, Riva 2009: 59-63). Dla dalszych rozważań szczególnie istotny jest brak mimiki i przekazu parawerbalnego jako najdoskonalszych sposobów wyrażania emocji w komunikacji bezpośredniej. Uwagę zwraca też duży stopień schematyzacji wypowiedzi, wynikający z ograniczeń interfejsu (opcja „lubię to”, bez możliwości zniuansowania natężenia „lubienia”).

Głębsze zmiany dotyczą charakteru więzi łączących uczestników portali społecznościowych oraz sposobu wyrażania przez nich emocji. Grupy wirtualne mają charakter „refleksyjny” (reflexive), tj. ludzie stają się ich członkami zgodnie ze swoją wolą, potrzebami i zainteresowaniami (Slevin 2008: 593), w przeciwieństwie do tradycyjnych wspólnot funkcjonujących na podstawie kryterium terytorialnego czy przymusu społecznego (Wallace 2005: 108-109; Podgórski 2006: 101-102). Łączą one ludzi bez „wspólnej 
przeszłości”. Z tego zapewne wynika zarówno duża liczba wypowiedzi explicite autoprezentacyjnych, jak i łatwość tworzenia fałszywych kreacji. Inne zjawiska, budzące niepokój psychologów i pedagogów, to efekt odhamowania i obniżony próg agresji. Brak więzi twarzą w twarz, blokujący reakcje empatyczne oraz poczucie anonimowości i bezkarności sprawiają, że ludzie łatwiej i szybciej odczuwają w kontaktach wirtualnych emocje negatywne i bardziej agresywnie je wyrażają (Grzenia 2003: 84; Wallace 2005: 147-176; Joinson 2009).

\section{4. Środki i sposoby wyrażania sympatii - analiza}

Prezentowane poniżej przykłady wypowiedzi pochodzą z facebookowych profili trzech osób publicznych: dziennikarki Moniki Olejnik (MO), polityka Janusza Korwin-Mikkego (JKM) oraz trenerki Ewy Chodakowskiej (ECh).

\section{1. Środki wyrażania sympatii}

\subsubsection{METAKOMUNIKACYJNE}

Najbardziej sformalizowanym sposobem wyrażenia sympatii umożliwianym przez interfejs serwisu jest „polubienie” (odznaczenie opcji „lubię to") danego profilu. W przypadku omawianych osób liczba fanów wynosi: ok. 75 tys. (MO), 294 tys. (JKM), 1,148 tys. (ECh) ${ }^{10}$. „Polubić” można także poszczególne wypowiedzi (,posty”) właścicieli strony, co jest wyrazem sympatii do osoby lub prezentowanych treści. Inną opcją systemową jest „udostępnienie” wypowiedzi na własnej osi czasu, ale tu motywy mogą być różne, niekoniecznie świadczące o sympatii. Użytkownicy mają świadomość uproszczenia wynikłego z tej standaryzacji. Jedna z fanek pyta:

(ECh) Jest taki guzik „Uwielbiam to”?"1,

\footnotetext{
${ }^{10}$ Dane na dzień 17.05.2014.

${ }^{11} \mathrm{Tu}$ i w kolejnych przykładach - pisownia oryginalna. Dostęp do cytowanych wypowiedzi: 17.05.2014.
} 
wyrażając tym samym „lubienie” o wyższym stopniu natężenia. Fani mogą też założyć fanpage (stronę dla sympatyków) danej osoby lub zmienić nazwę własnego profilu na znaczącą i wyrażającą sympatię do niej:

(ECh) Pot to tłuste łzy, Ewa moje życie, Ewa Chodakowska - fanka; (JKM) Max Korwin Cejrowski, Głosuję na Korwina.

\subsubsection{JĘZYKOWE}

Wbrew obawom krytyków Internetu jako medium obrazkowego, język w jego elektronicznej wersji pozostaje głównym kodem komunikacyjnym. Jest to pismo niestaranne w zakresie składni i leksyki, graficznie odpowiadające mówionemu językowi potocznemu, pełne błędów literowych i anakolutów. Użytkownicy nie stosują się do norm ortograficznych i interpunkcyjnych (przynajmniej tych obowiązujących w ,realu”), piszą językiem kolokwialnym, używają skrótów i emotikonów (Grzenia 2007: 105-107, 119-126). W zakresie badanych aktów komunikacyjnych uwagę zwracają zwłaszcza dwa zjawiska. Po pierwsze, miejsce ,ja” i „ty” w wypowiedzi. Interpersonalne wyrażanie uczucia sympatii zakłada strukturę ,ja czuję sympatię do ciebie” (czasem zamiast ,ja” pojawia się „my” o funkcji socjalizującej), taka też jest najpowszechniejsza rama pragmatyczna tego typu aktów (wyrażana na poziomie illokucji, niekoniecznie lokucji):

(ECh) chałam zaznaczyc ze turbo mnie poniewiera dzieki Tobie moje życie jest inne... lepsze dziekuje!

(JKM) stary, masz mój głos.

(ECh) Moja ,Nasza Kochana Ty!

Równie popularne są wypowiedzi niekierowane bezpośrednio do adresata, a do wszystkich odbiorców. Struktura ta (,ja mówię wam, że czuję sympatię do niego") odzwierciedla świadomość szerszej publiczności u nadawcy:

(JKM) Korwin mądrze gada. Polac mu co on tam pije.

Zdarzają się także wypowiedzi łączące oba schematy:

(JKM) gdyby Korwin trochę lżej mówił i innym językiem już dawno byłby w sejmie, mimo to ma Pan mój głos na bank, ale dalszy styl tych apeli, a niestety nie damy rady 
(obym się mylił). Za mała siła przebicia, a „lajki” nie wpływają zbytnio na rzeczywistość. Mimo wszystko głos kilku znajomych i mój sam ma Pan!

Część wypowiedzi wydaje się nie zawierać ukierunkowania na odbiorcę, jednak analiza intencjonalności pozwala założyć, że mają one taką właśnie podwójną strukturę - są kierowane zarówno do adresata, jak i do pozostałych obiorców wypowiedzi:

(MO) No nie dość, że świetna redaktorka, to ostra jak chili modelka.

Drugie interesujące zjawisko to stylizacja języka na odmianę socjolektalną, typową dla danego profilu - samego właściciela i innych użytkowników. Na tę swoistą mimikrę językową składają się szczególnie często używane słowa klucze (ECh: „motywacja”, „motywatorka”, ,walka”), powiązane ze światopoglądem słownictwo nacechowane aksjologicznie i emocjonalnie (JKM: „d...kracja”, „liberalny”, „oszuści”), inne leksemy nacechowane emocjonalnie (JKM: wulgaryzmy i obelgi, ECh: zdrobnienia), różne style interpunkcyjne, treść emocjonalna (ECh) lub rzeczowa i quasi-logiczna (JKM), różne formy adresatywne:

(JKM) Jak Pan Janusz nie ogarnie tego burdelu to szlag trafi tą Polskę !!!

(JKM) K....wa Panie Januszu niech Pan tego nie zmarnuje!!!!!

(ECh) A ja byłam w lutym we Wrocławiu na warsztatach i dostałam porządnego „kopa motywacyjnego" od samej Ewci dziennik jest mega, uzupełniam od dwóch tygodni i nie da rady zostawić puste okienko ! z dnia na dzień ćwiczenia coraz lepiej wychodzą i juz widze malutkie pierwsze zmiany (...) a z kalendarza Ewcia się uśmiecha i mówi „, Blondyna dawaj dawaj „,! Ewcia moje guru ukochane dziękuję Ci za to że jesteś z nami !!

(ECh) Książka i ćwiczenia rewelacja Na to czekałam... Uśmiech od ucha do ucha i już pierwszy przepis na śniadanko został wykorzystany Dziękuję Ewcia Twoje filmiki, zdjęcia, książki, a przede wszystkim motywacja - to TY sprawiasz, że każdego dnia chce się więcej I dzień staje się piękniejszy.

Dopasowanie stylu wypowiedzi do używanego przez obiekt sympatii i jego zwolenników, innymi słowy: odpowiednik niewerbalnego zjawiska „lustrzanego odbicia”, również jest sposobem wyrażenia sympatii. Pełni przy tym funkcję socjalizacyjną i podkreśla więź nadawcy z adresatem i odbiorcami. 


\subsubsection{OBRAZOWE I PARAJĘZYKOWE}

Interfejs większości serwisów społecznościowych umożliwia, oprócz wpisywania tekstu, także wstawianie obrazków lub filmów. Przekazy obrazkowe mogą służyć wyrażaniu sympatii, np. zdjęcie bukietu kwiatów czy serca. Nieporównywalnie częściej pojawiają się jednak w tej funkcji emotikony, czyli skonwencjonalizowane obrazki, nawiązujące do wyrazów twarzy (uśmiechy, pocałunek) lub symbolizujące emocje (serce, gest ok). Emotikony są uznawane za podstawowy wirtualny sposób wyrażania uczuć, służą także innym celom (np. zaznaczaniu modalności; Grzenia 2003: 138).

Podobne funkcje - wyrażanie emocji i modalności - pełnią w e-piśmie znaki interpunkcyjne, przy czym najchętniej używanymi symbolami są wykrzykniki, oznaczające siłę emocjonalnego pobudzenia, oraz wielokropki, które pełnią różne funkcje. Do wyrażania intensywności emocji, a także akcentowania ważnych elementów wypowiedzi, służy też pisownia dużymi literami.

(MO) Super!!!!!!!!!! Dziewczyny góra! A starym zazdrosnikom mówimy za sp. pamięci prezydentem :s.... Dziadu :)))

(ECh) JESTEŚ WIELKA!!!

\subsection{Intencjonalność wypowiedzi wyrażających emocje}

Sympatia w zbadanym zbiorze wypowiedzi jest okazywana na ogół za pomocą aktów mowy określanych w Searle'owskiej typologii jako ekspresywy, czyli akty wyrażające pewien stan psychiczny. Stan ów w badanych przypadkach dotyczy odczuwania sympatii do drugiej osoby. Funkcja emotywna jest wyrażana w sposób bezpośredni lub pośredni, ale pragmatycznie jawny, odczytywalny z presupozycji (presupozycją aktu komplementowania czy wyznania uczuć jest odczuwanie sympatii), konwencjonalnych implikatur („człowiek myślący przyzna Panu rację”) lub pozytywnych konotacji (,kobieta z jajami”). Funkcji tej towarzyszą przeważnie inne, dodatkowe, przede wszystkim fatyczna (podkreślająca poczucie więzi i akceptacji), autoprezentacyjna (kreująca ,ja”), poznawcza (prezentacja poglądów), konatywna (prośba o reakcję). Poniżej 
przedstawiam przykłady najczęściej występujących typów aktów mowy ze względu na jego szczegółową intencję oraz treść ${ }^{12}$.

\subsubsection{KOMPLEMENTY, WYRAZY POPARCIA I GRATULACJE (CZUJĘ DO CIEBIE SYMPATIĘ, BO NA TO ZASŁUGUJESZ):}

(MO) Madonna ale wersja intelektualna!

(JKM) Ma pan piękny język. Nie za sztywny i nie za głupi, a jednocześnie mówi pan prawdę, o którą trudną w tym dzisiejszym dekadenckim świecie.

(MO) piszcie sobie co chcecie... ale Monika Jedna z niewielu kobiet na luzie i jednocześnie z jajami...o ile ze tak moge trywialnie się wyrazić.

(MO) Dobrze że jesteś i punktujesz tych pajaców dzis w ogole kobiety sa odważniejsze niż meszczyżni robisz dobrą robotę.

(JKM) Ogladalam program w tv. Panie Mikke jest Pan moim ulubieńcem!!! Kazdy myślący czlowiek przyzna Panu rację.(...) PAN MOWI TO CO WSZYSCY Z IQ WYZSZYM NIZ 3XROZMIAR BUTA WIDZĄ I WIEDZĄ. niestety w PL, zreszta na calym świecie jesteśmy w mniejszosci. Reszta łyka jak gęsi cala te propagandę i nic sie na to nie poradzi. pozdrawiam serdecznie. Koriwn na prezydenta!!! Gratulacje.

\subsubsection{PODZIĘKOWANIA (CZUJĘ DO CIEBIE SYMPATIĘ, BO COŚ CI ZAWDZIĘCZAM):}

(ECh) Dzieki Ewa jestes wielka buziole pozdrawiam dzieki Tobie wszystko staje sie inne.

(ECh) dobranoc:)dziekuje za zakwasy na dzisiejszy wieczor:)ala:(

(ECh) Dziękuję Pani Ewo!!To właśnie dzięki Pani zaoszczędzamy masę czasu!!Wszystko podane, cudnie, jest Pani niesamowita, tak jak my się nie zniechęcamy, proszę się też nie przejmować różnymi „dziwami”i nas nie zostawiać.To co Pani robi ma ogromny sens!!!!!

4.2.3. WYZNANIA UCZUĆ (CZUJĘ DO CIEBIE SYMPATIĘ I CHCĘ ŻEBYŚ TO WIEDZIAŁ/A), NAJBLIŻSZE CZYSTEJ EKSPRESJI SYMPATII:

(MO) Lubię Cię Monia :))

(ECh) uwielbiamy Cię Ewciu $<3$

(JKM) Janusz jesteś najlepszy!!szacunek...

\subsection{4. ŻYCZENIA (CZUJĘ DO CIEBIE SYMPATIĘ I CHCĘ DLA CIEBIE CZEGOŚ DOBREGO):}

(MO) Moniko i miłego wszystkiego znaczy byś była uśmiechnięta i wesoła i dodam taką radę więcej wesołości mimo cudzej złości

${ }^{12}$ Duża część przytaczanych wypowiedzi zawiera w swojej strukturze kilka prostych aktów mowy; określam ich typ ze względu na dominującą intencję całej wypowiedzi. 
(JKM) Bardzo dobre wystąpienie ! Mniej emocji i więcej merytoryki ! Oby tak dalej. Powodzenia w Eurowyborach.

(JKM) Panie Januszu, życzę zdrowia! Ten kaszel Pana męczy z wystąpienia na wystąpienie coraz bardziej. Proszę o siebie dbać!

\subsubsection{AUTOPREZENTACJE (CHCĘ POWIEDZIEĆ O SOBIE COŚ, CO JEST ZWIĄZANE Z SYMPATIĄ DO CIEBIE), AKTY EKSPRESYWNO-ASERTYWNE:}

(MO) Ja jestem w wieku pani Moniki i jak widać też nie lubię się czesać i ścinać włosów - niepokorne natury tak mają...

(ECh) Ewa kurcze jestes juz we dnie i w nocy......mysl co chcesz ale snilas sie mi dzis w nocy I krzyczalas ze mam walczyc I sie nie poddawac I ze na pewno dam rade mimo wszystko.

\subsubsection{DEKLARACJE (CHCĘ OBIECAĆ COŚ, CO JEST ZWIĄZANE Z SYMPATIĄ DO CIEBIE), AKTY EKSPRESYWNO-KOMISYWNE:}

(JKM) Jedyny gość, którego lubię i szanuję jeśli chodzi o politykę. Zawsze na niego głosuję i mam w dupie, że zdobywa kilka procent. Tu chodzi o prawdę i honor. Bez względu na sondaże ZAWSZE GŁOSUJCIE ZGODNIE Z WŁASNYM SUMIENIEM!!!

(JKM) Wierze w Korwina Mikke i będę na niego głosował.

\subsubsection{PROŚBY I PROPOZYCJE (CZUJĘ DO CIEBIE SYMPATIĘ I LICZĘ NA WZAJEMNOŚĆ), AKTY ESPRESYWNO-OBLIGATYWNE:}

(ECh) Kupione Ewa bądź ze mną mam nadzieje ze mi sie uda.

(ECh) Popieram jak najbardziej to co robisz Ewo mimo ze jestem facetem.Jestem takze $\mathrm{z}$ tego srodowiska poniewaz mam badzo dluga i bogata przeszlose $\mathrm{w}$ roli kucharza, od wielu lat jestem tez dietetykiem i massage therapist.Jesli moglbym sie na cos przydac to bardzo chetnie bede wspolpracowal. Pozdrawiam z UK.

\section{Wnioski}

Sympatia w zbadanym środowisku komunikacyjnym wyraża się przede wszystkim w ekspresywnych aktach mowy, rzadziej w obligatywnych i komisywnych. Wiele z nich ma charakter złożonych wypowiedzi, gdyż funkcja emotywna realizuje się raczej w komunikatach nawiązujących do kontekstu i spełniających także dodatkowe funkcje (konatywną, 
poznawczą, fatyczną) niż w czystych ekspresjach. Ich intencja jest wyrażana bezpośrednio lub pośrednio jako presupozycja, implikatura lub treść konotowana. Rama pragmatyczna obejmuje wyrażenie się nadawcy oraz jego relację z obiektem sympatii. Cechy różniące sposoby wyrażania sympatii $\mathrm{w}$ rozmowie bezpośredniej i internetowej to:

- podwójna rama pragmatyczna ,ja” - „ty” (adresat i obiekt sympatii) i ,ja” - „wy” (wszyscy potencjalni odbiorcy), związana z nowym miejscem komunikacji, w którym przekaz jest prywatny i publiczny równocześnie;

- inne środki semiotyczne i pragmatyczne - elektroniczna wersja pisma wspierana elementami obrazkowymi; aktualnie obserwowane użycie tych środków wskazuje na poszukiwanie i konstytuowanie się nowych sposobów wyrażania emocji, zwłaszcza środków wyrażania treści i natężenia emocji; do najważniejszych należą: stylizacja „lustrzana”, emotikony, nowe zastosowanie interpunkcji, mechanizmy przekazywania treści niejawnych, skrypty ekspresywnych aktów mowy;

- większe natężenie emocji; zjawisko obniżenia progu odczuwania emocji dotyczy nie tylko zachowań negatywnych, ale także pozytywnych, przynajmniej w badanym środowisku; dalszych badań wymaga kwestia autentyczności siły emocjonalnej - czy realnie odczuwana emocja rzeczywiście jest mocniejsza, czy tylko jej semiotyczny wyraz ma hiperbolizujący charakter.

\section{Literatura}

Antas J., 2000, O kłamstwie i kłamaniu. Studium semantyczno-pragmatyczne, Kraków. Chudzik A., 2012, Reguty konwersacji na forum internetowym - tradycja a innowacja, „Annales Universitatis Paedagogicae Cracoviensis - Studia Linguistica”, t. 7, Dia$\log z$ tradycja, cz. 2, s. 77-85.

Drabik B., 2004, Komplement i komplementowanie jako akt mowy $i$ komunikacyjna strategia, Kraków.

Dunaj B. (red.), 1996, Słownik współczesnego języka polskiego, t. 2, Warszawa.

Furdal A., 2000, Językoznawstwo otwarte, Wrocław.

Galimberti C., Riva G., 2009, Aktorzy, artefakty i procesy. Szkic społecznej psychologii cyberprzestrzeni, w: Internet a psychologia. Możliwości i zagrożenia, red. W.J. Paluchowski, przeł. A. Krawulska-Ptaszyńska, Warszawa, s. 46-71.

Goleman D., 1997, Inteligencja emocjonalna, przeł. A. Jankowski, Poznań. 
Grzegorczykowa R., 1991, Problem funkcji języka i tekstu w świetle teorii aktów mowy, w: Język a kultura, t. 4, Funkcje języka $i$ wypowiedzi, red. J. Bartmiński, R. Grzegorczykowa, Wrocław, s. 11-28.

Grzegorczykowa R., 2001, Wprowadzenie do semantyki językoznawczej, Warszawa.

Grzenia J., 2003, Internet jako miejsce dialogu, w: Porozmawiajmy o rozmowie. Lingwistyczne aspekty dialogu, red. M. Kita, Katowice, s. 81-90.

Grzenia J., 2007, Komunikacja językowa w Internecie, Warszawa.

Jakobson R., 1989, W poszukiwaniu istoty języka, t. 2, wybór, red. nauk. M.R. Mayenowa, Warszawa.

Joinson A.N., 2009, Przyczyny i skutki rozhamowanego zachowania $w$ Internecie, w: Internet a psychologia. Możliwości i zagrożenia, red. W.J. Paluchowski, przeł.

A. Nadolska, Warszawa, s. 135-157.

Pisarek W., 2008, Wstęp do nauki o komunikowaniu, Warszawa.

Pisarkowa K., 1994, Język wedtug Junga. O czytaniu intencji, Kraków.

Podgórski M., 2006, Wirtualne spoteczności $i$ ich mieszkańcy. Próba e-tnografii, w: E-seje z socjologii Internetu, red. J. Kurczewski, Warszawa, s. 75-209.

Polański K. (red.), 2003, Encyklopedia językoznawstwa ogólnego, Wrocław-Warszawa-Kraków.

Postman N., 2002, Zabawić się na śmierć. Dyskurs publiczny w epoce show-businessu, przeł. L. Niedzielski, Warszawa.

Schultz von Thun F., 2001, Sztuka rozmawiania, t. 1, Analiza zaburzeń, przeł. P. Włodyga, Kraków.

Searle J.R., 1987, Czynności mowy: rozważania z filozofii języka, przeł. B. Chwedeńczuk, Warszawa.

Slevin J., 2008, Internet i formy związów ludzkich, w: Socjologia codzienności, red. P. Sztompka, M. Bogunia-Borowska, przeł. M. Juza, Kraków, s. 593-627.

Strelau J., Jurkowski A., Putkiewicz Z., 1975, Podstawy psychologii dla nauczycieli, Poznań.

Tabakowska E. (red.), 2001, Kognitywne podstawy języka i językoznawstwa, Kraków. Wallace P., 2005, Psychologia Internetu, przeł. T. Hornowski, Poznań.

Watzlawick P., Beavin Beavels J., Jackson D.D., 1967, Pragmatics of Human Coтmunication, New York.

Winterhoff-Spurk P., 2007, Psychologia mediów, przeł. P. Włodyga, Kraków.

\section{Źródla internetowe}

Stownik języka polskiego PWN, <http://sjp.pwn.pl>, 20.04.2014. 